\title{
The functional logic of cytosolic 5'-nucleotidases
}

2

3

Piero L. Ipata*, Francesco Balestri

4

5 Department of Biology, Unit of Biochemistry, University of Pisa, Via San Zeno 51, Pisa, Italy

6

7

8

9

10 Correspondence*: Prof. Piero Luigi Ipata, Department of Biology, Unit of Biochemistry -

11 University of Pisa, Via San Zeno 51, 56127 Pisa, Italy. Phone: +390502211462, Fax:

$12+390502211460$, email: plipata@ biologia.unipi.it

13

14

15

16 Running title: Biochemistry of cytosolic 5'-nucleotidases

17

18

19

20

21

22

23 


\section{Abstract}

Adenosine- and uridine-cytidine kinases, purine-nucleoside phosphorylase, hypoxanthine-guanine phosphoribosyltransferase, and several related enzymes, are components of the salvage pathways which reduce the loss of intracellular purine and pyrimidine rings. Although this could explain the role of these enzymes, it poses a problem of the role of the cytosolic 5'-nucleotidase. Why are nucleosides produced from nucleoside-monophosphates, only to be converted back to the same compounds? To date, it is well established that a cross talk exists between the extracellular and intracellular nucleoside metabolism. In districts, such as brain, which are dependent on salvage nucleotide synthesis, nucleosides are produced through the action of the ecto-5'-nucleotidase, the

11 last component a series of plasma-membrane bound enzyme proteins, catalyzing the successive 12 dephosphorylation of released nucleoside-triphosphates. Both nucleoside-triphosphates (mainly 13 ATP and UTP) and nucleosides (mainly adenosine), act as extracellular signals. Once transported into cell cytosol, all nucleosides are salvaged back to nucleoside-triphosphates, with the exception of inosine, whose salvage is limited to IMP. Intracellular balance of nucleosides is maintained by the action of several enzymes, such as adenosine deaminase, uridine phosphorylase and cytidine deaminase, and by at least three 5'-nucleotidases, the ADP activated AMP preferring cN-IA, the ATP-ADP activated IMP-GMP preferring cN-II, and the UMP-CMP preferring cN-III. Here we are reviewing the mechanisms whereby cytosolic 5'-nucleotidases control changes in nucleoside and nucleotide concentration, with the aim to provide a common basis for the study of the relationship between biochemistry and other related disciplines, such as physiology and pharmacology.

Key words: 5'-nucleotidases, cN-IA; cN-II, cN-III, nucleoside utilization, nucleoside recycling 
HISTORICAL HINTS AND A BRIEF OVERLOOK

Changes in the concentration of intra- and extracellular nucleosides (NSs) regulate a number of physiological processes in man (e.g. neurotransmission, blood flow, lipolysis [1-6], membrane phospholipid synthesis and synapse generation [7-10]), and brain energetics [11-14]. In most tissues NSs are produced by nucleoside-5'-monophosphates (NMPs) dephosphorylation, an enzyme activity first reported in 1934 by Reis to dephosphorylate AMP and IMP in heart and skeletal muscle [15]. It has long been assumed that, in order to exert their functions, nucleosides should be released from the cells. For instance, adenosine is produced intracellularly by 5 '-nuceotidase, and is then transported across the cell membrane by the equilibrative nucleoside transport (ENT) system according to its concentration gradient. However, as discussed by Arch and Newsholme in 1978 in their seminal paper on adenosine metabolism [16], the problem with this hypothesis is the localization of 5'-nucleotidase. Indeed, cytochemical, histochemical, and cell fractionation studies have unequivocally shown that 5'-nucleotidase activity is associated with plasma membrane in many tissues [16-18], and acts as an ecto-enzyme. It was then hypothesized that the nucleotidase hydrolyzes exclusively extracellular NMPs, and NSs are then transported into the cell. However, in 1988 Truong et al. described in rat heart a cytosolic 5'-nucleotidase, whose kinetic and regulatory properties differ markedly from those of the plasma membrane associated 5'-nucleotidase [19]. This nucleotidase is highly specific for AMP, with a $K_{\mathrm{m}}$ value in the $\mathrm{mM}$ range (vs. the broad specificity and $\mu \mathrm{M} K_{\mathrm{m}}$ range of the membrane bound enzyme) and is activated by ADP, but not by ATP [20, 21]. On the contrary the membrane bound enzyme is strongly inhibited by both ADP and ATP [2225]. It has been hypothesized that AMP specific 5'-nucleotidase has a physiological function in adenosine generation during ischemia, when ATP is actively broken down, and AMP accumulates [23-25]. Another important cytoplasmic 5'-nucleotidase, first identified by Itoh in 1967 [26], preferentially dephosphorylates IMP and GMP, and is highly sensitive to ATP activation [27-29]. A pyrimidine 5'-nucleotidase, specific for UMP and CMP, is highly expressed in reticulocytes, and is assumed to participate in the process of erythrocyte maturation [30,31]. Other 5'-nucleotidases, with different specificity for natural nucleoside- and deoxynucleoside-5'-monophosphates, have been described in the cytosol and in mitochondria of diverse tissues and organs. As discussed by Bianchi and Spychala [32], "the presence in human genome of at least seven genes for 5'nucleotidases suggests that these enzymes perform important metabolic functions".

To date it is well established that the plasma membrane bound ecto-5'-nucleotidase is the last component of a signaling cascade that hydrolyses extracellular nucleoside tri-phosphates (NTPs) to NSs [23-25]. Here we are reviewing the mechanisms whereby cytosolic 5'-nucleotidases 
1 control changes in NSs concentration, with the aim to provide a common basis for the study of the

2 relationship between biochemistry and other related disciplines, such as physiology and

3 pharmacology. The nomenclature of cytosolic 5'-nucleotidases reported by Bianchi and Spychala

4 [32] will be used throughout this review.

AMP ACCUMULATES FROM ATP BREAKDOWN AS A SIGNAL OF ISCHEMIC CONDITION, AND IS DEPHOSPHORYLATED BY CN-IA NUCLEOTIDASE

and by the relatively specific nucleoside mono- and diphosphate kinases: enters the mitochondria, to fuel oxidative phosphorylation, thus contributing in maintaining a relatively constant normoxic ATP concentration $(\sim 5 \mathrm{mM})[16]$. The time courses of ATP breakdown and of ATP catabolites formation in "post-mitochondrial" extracts of rat brain [23] (Fig. 
1 2A) strongly suggest that at normoxic ATP levels AMP is catabolized to Ino and hypoxanthine

2 (Hyp) through the successive action of two ATP activated enzyme proteins, AMP deaminase

3 (AMPD) and IMP-GMP preferring 5'-nucleotidase (cN-II), followed by purine nucleoside phosphorylase (PNP) (the so called "IMP pathway" ATP $\rightarrow$ ADP $\rightarrow$ AMP $\rightarrow$ IMP $\rightarrow$ Ino $\rightarrow$ Hyp), rather than being dephosphorylated to Ado. The inset of Fig. (2A) shows that the production of Ino and Hyp precedes that of the minute amount of Ado, thus excluding a precursor-product relationship between Ado and Ino plus Hyp formation. Moreover, Ado started to be formed only at ATP concentration close to the ischemic levels. It can be hypothesized that in normoxic condition the AMP preferring cN-IA remains silent. At ischemic ATP initial concentrations (Fig. 2B) we are faced with a different scenario: AMP is catabolized to Ino and hypoxanthine through the successive actions of the ADP activated cN-IA, adenosine deaminase (AdoD), and of PNP (the so called "adenosine pathway" ATP $\rightarrow$ ADP $\rightarrow$ AMP $\rightarrow$ Ado $\rightarrow$ Ino $\rightarrow$ Hyp), rather than being deaminated to IMP. It can be hypothesized that in ischemic condition both AMPD and cN-II are deactivated by the low ATP level. In addition, both enzymes are strongly inhibited by the $\mathrm{P}_{\mathrm{i}}$ level, reaching a value of $82 \mathrm{mM}$ in ischemic condition [41]. adenosine pathway [46].

\section{AMP MODULATES THE ENERGY METABOLISM IN MAN}

In 1963 Hans Krebs pointed out that the cellular AMP concentrations change more dramatically than those of ADP and ATP [47]. For a discussion on this important issue see Ref. [48]. One year later Ramaiah, Hathaway, and Atkinson showed that AMP (or the [AMP]/[ATP] ratio) is the main metabolic regulator of yeast phosphofructokinase [49], an enzyme quite similar to those from various animal sources. To date the $[\mathrm{AMP}] /[\mathrm{ATP}]$ ratio is considered to be a signal of compromised energy status of the cell [48]. AMP "senses" this abnormal condition, and exerts a pivotal effect on the regulation of cellular and whole body metabolism. AMP interacts either 
1 directly with key catabolic regulatory enzyme proteins, or indirectly through an ATP activated protein kinase, named AMPK. AMP binds to the allosteric sites of muscle glycogen phosphorylase, and stabilizes its active conformation [50-52]. The activity of muscle 6-phosphofructokinase is modulated by a number of allosteric regulators, including AMP and ATP. Adenine nucleotides implement their allosteric inhibitory (ATP) and activating (AMP) effects by binding to different allosteric sites [53-56]. During cellular stresses that deplete ATP, and consequently elevate AMP concentration, AMP specifically binds to one of the subunits of AMPK and switches off ATP consuming anabolic pathways, while switching on the ATP producing catabolic pathways, thus restoring the physiological ATP level [57-61] (Fig. 3).

\section{Figure 3}

It may be speculated that fluctuations of AMP concentrations in cell cytosol, modulated by $\mathrm{cN}-\mathrm{IA}$ and AMPD, may influence AMPK activity [62, 63]. Accordingly, silencing cN-IA in human and mouse muscle increases the $[\mathrm{AMP}] /[\mathrm{ATP}]$ ratio, activates AMPK and stimulates AMP downstream signalling [64]. Conversely, overexpression of cN-IA decreases AMPK activation [65]. In no-flow ischemia the increased intracellular AMP concentration, due to the massive ATP breakdown and to the inhibition of $\mathrm{cN}-\mathrm{IA}$ at pH 6.3 activated AMPK. On reflow the physiological $\mathrm{pH}$ relieves the inhibition, and physiological low AMP concentration is restored [62]. Other abnormal, pathological stresses, including heat shock, metabolic poisons, glucose deprivation [66, 67], activate AMPK by interfering with decreased ATP production from AMP. Conversely physical exercise, a physiological stress [68], activates AMPK by interfering with increased ATP consumption, a condition leading to AMP accumulation [48]. Finally, Metformin, the most widely used drug for type II diabetes [69], activates AMPK through inhibition of AMP deaminase [70]. Taken together, these observations suggest that cN-IA and AMPD, two key enzymes of the AMP catabolic pathways, may effectively modulate the energy metabolism in man.

\section{THE IMP-GMP PREFERRING 5'-NUCLEOTIDASE cN-II}

The physiological role of cN-II, an ubiquitous enzyme [71-73], has not been clearly defined yet. As a catabolic enzyme, $\mathrm{cN}$-II, as well as cN-III, generate free diffusible nucleosides in the liver, to be delivered to other organs, such as brain, which depend on preformed purine and pyrimidine rings for the synthesis of nucleotides [37]. In early 1980 Guha and Rose showed that brain glucose1,6-bisphosphatase (later shown to correspond to the previously described enzyme

31 phosphomannomutase [74]) is highly sensitive to activation by IMP [75,76]. Glucose-1,6bisphosphate has been identified as a modulator of rate limiting enzymes of glycolysis $[75,76]$. 
1 Thus, it might be hypothesized that fluctuations of IMP levels, modulated by $\mathrm{cN}-\mathrm{II}$, might play a role in the control of ATP concentration. Convincing evidence on the role of $\mathrm{cN}-\mathrm{II}$ in cell viability has been obtained [77]: its wide distribution, its intricate regulatory properties [73, 78-80] and its capacity to transfer the phosphate group of the substrate IMP not only to water (the 5 '-nucleotidase activity), but also to the 5' or 3'-OH group of a nucleoside acceptor (the phosphotransferase activity $[81,82])$, strongly suggest that $\mathrm{cN}-\mathrm{II}$ might contribute in maintaining the qualitative and quantitative balance of intracellular purine rings.

THE PURINE NUCLEOTIDE CYCLE AND THE OXYPURINE CYCLE

The purine nucleotide cycle (PNC), first described by Goodman and Lowenstein in 1977 [83] is composed of three reactions, catalyzed by cytosolic adenylate deaminase, adenylosuccinate synthase, and adenylosuccinate lyase (enzymes 4, 5, and 6 of Fig. (4)):

$$
\mathrm{AMP}+\mathrm{H}^{+}+\mathrm{H}_{2} \mathrm{O} \rightarrow \mathrm{IMP}+\mathrm{NH}_{4}{ }^{+} \quad \text { adenylate deaminase }
$$

$\mathrm{IMP}+\mathrm{GTP}+$ aspartate $\rightarrow \mathrm{S}-\mathrm{AMP}+\mathrm{GDP}+\mathrm{Pi}+2 \mathrm{H}^{+} \quad$ adenylosuccinate synthase

The summary equation:

$$
\mathrm{GTP}+\text { aspartate }+\mathrm{H}_{2} \mathrm{O} \rightarrow \mathrm{GDP}+\mathrm{Pi}+\text { fumarate }+\mathrm{NH}_{4}{ }^{+}+\mathrm{H}^{+}
$$

shows that the cycle turns over at the expense of GTP and aspartate.

The PNC is particularly active in skeletal muscle, under conditions associated with increased rate of glycolysis [83, 84]. During exercise, when the velocity of myosin ATPase does not match the capacity of contracting muscle to phosphorylate ADP by glycolysis or oxidative phosphorylation, the concentrations of AMP rise (Fig. 4), leading to deamination of AMP to IMP, thus to activation of the PNC. Since PNC intermediates, AMP, IMP, and adenylosuccinate (SAMP) are non-diffusible charged purines, the PNC favours a rapid return of the ATP stores to the resting level after a short oxygen independent bout, e.g., a 100-m sprint [85]. Deficiency of AMPD, one of the enzymes of PNC, is present in 2\% of healthy population [86], and is associated with lower exercise performance [87]. During sustained oxygen independent exercise, e.g., a 400-m sprint, or during repeated short-sprint bouts, when the velocity of ATP hydrolysis by myosin ATPase markedly exceeds that of ATP re-synthesis [85, 88-93], IMP accumulates, thus increasing the rate of IMP dephosphorylation by $\mathrm{cN}-\mathrm{II}$, and, consequently, the rate of Ino and Hyp production, 
1 which are transported into the bloodstream to be either excreted by the urine or imported into liver,

2 where they are oxidized to urate [94].

Alternatively, IMP may enter an additional purine cycle, named oxypurine cycle (OPC), first described by Barankiewitz in mononuclear cells and fibroblasts in 1982 [95]. The OPC is composed shows that the cycle turns over at the expense of PRPP, a high energy sugar phosphate with a high potential of 5-phosphorybosyl transfer. A widely accepted tenet is that the PRPP pool is maintained at a low level, to avoid excessive and unbalanced nucleotide synthesis. Because the net reaction of the OPC is the hydrolysis of PRPP, OPC has been proposed to play a role in the metabolic regulation of PRPP levels [95-97] (Figure 4).

The summary equation:

$$
\mathrm{PRPP}+\mathrm{H}_{2} \mathrm{O} \rightarrow \text { Rib-1-P }+\mathrm{PP}_{\mathrm{i}}
$$

$c N-I I$

PNP

$H P R T$

As shown in Fig. 5, while PRPP is being consumed, IMP, Ino, and Hyp attain a steady state level, and are continuously recycled. But as soon as PRPP disappears, HPRT becomes inactive, and the cycle collapses, causing IMP degradation and Hyp accumulation. The cycle has been reconstructed “in vitro" [97], by using commercial HPRT, PNP, and a highly purified preparation of cN-II, cloned and expressed in Escherichia coli. The kinetics was strikingly similar to that observed when crude extracts of rat brain were used as an enzyme source (Fig. 5).

Figure 5

25 Although the OPC might contribute in maintaining the cytoplasmic concentration of IMP at the expense PRPP, the two unphosphorylated intermediates, Ino and Hyp, are easily transported into the blood stream. Similar cycles, involving AMP, Ado and adenine, or IMP, Ino and Hyp, cannot be 
operative in man, owing to the absence of adenosine phosphorylase [98] and inosine kinase [99] in mammals. Finally, it should be noted that the PNC and the OPC are interconnected by IMP, a common intermediate acting as a substrate of S-AMP synthase and of $\mathrm{cN}-\mathrm{II}$ in the PNC and the OPC, respectively. However, to our knowledge the metabolic features of this issue have not been investigated.

\section{THE FUNCTION OF PYRIMIDINE NMP PREFERRING CYTOSOLIC 5'-} NUCLEOTIDASE

The dephosphorylation of cytosolic pyrimidine NMPs to their corresponding nucleosides is catalyzed by pyrimidine 5'-nucleotidase $\mathrm{cN}$-III [100-103]. The enzyme preferentially catalyzes the dephosphorylation of UMP and CMP, although it can act on pyrimidine antineoplastic agents as 5'AZTMP and 5'-Ara-CMP. A cytosolic isozyme of cN-III (P5' N-II or PN-2, or dNT-1) hydrolyzes the deoxy counterparts of UMP and CMP $[104,105]$. The activity of $\mathrm{cN}-\mathrm{III}$ increases concomitantly with erythrocyte maturation, and is followed by a further continuous decline throughout the ageing of the cell [106], suggesting that it plays a major role in the elimination of pyrimidine nucleosides formed from RNA degradation during erythropoiesis [107]. This hypothesis is in accord with the observed accumulation of pyrimidine nucleotides within the erythrocyte stroma of patients affected by haemolytic anemia caused by cN-III deficiency [108-110]. Human erythrocyte cN-III is identical to $\mathrm{p} 36$, an interferon- $\alpha$-induced protein associated with lupus inclusions $[111,112]$. The significance of the identity of the two proteins is at the moment obscure. The mRNA turnover releases, in addition to the four regular nucleoside monophosphates, the methylated cap nucleotide in the form of 7-methylguanosine monophosphate (m(7)GMP) or diphosphate (m(7)GDP). A novel 5'-nucleotidase recently identified in Drosophila and in man preferentially cleaves UMP and m(7)GMP to uridine and 7-methylguanosine, respectively [113]. cN-III plays an important role also in the balance of Urd. At least in neuronal and glial cells Urd homeostasis is maintained by the concerted action of UrdK, UPase, and cN-III. The rationale of the underlying molecular mechanism is the following. Urd enters neuronal and glial cells via the $\mathrm{Na}^{+}$-dependent, high affinity, concentrative nucleoside transporter (CNT) proteins or the equilibrative nucleoside transporter (ENT) proteins [114]. The balance between its anabolism and catabolism is maintained by UrdK, catalyzing the first step of UTP and CTP salvage synthesis, UPase, catalyzing the first step of uridine degradation, and by the inhibition exerted on UrdK by high levels of UTP and CTP, a signal 
1 generate a substrate cycle between UMP and uridine, similar to the AMP-adenosine cycle [16, 116,

2 117] (Fig. 6).

Figure 6

\section{NUCLEOSIDE RECYCLING IN THE BRAIN}

6 The rate limiting reactions of nucleotide synthesis are modulated by intracellular fluctuations of NMP, NDP, and NTP concentrations. This topic has been mostly studied at the level of the de novo nucleotide synthesis from simple precursors, mainly in liver [34]. However, there are districts, such as brain, which rely more heavily on the salvage of preformed purine and pyrimidine rings, in the form of nucleosides [37]. This raises the following question: how does brain maintain the right

11 balance between the purine and pyrimidine pools? We believe that it is now safe to state that a cross 12 talk exists between the extra- and intracellular metabolism of purine (Fig. 7) and pyrimidine NSs 13 (Fig. 8) in the brain. This interplay occurs between the extracellular milieu and the cytosol of a 14 single cell, or between adjacent cells, e.g. between two astrocytes [118] or between an astrocyte and 15 a neuron [119]. ATP and UTP, two important signalling molecules, are present in very small cytosolic vesicles and/or granules, at a concentration much higher than in the surrounding cytosol [25]. The low specificity of the vesicular nucleoside transporters may explain the presence of additional nucleoside triphosphates, such as GTP [25] and possibly CTP [120] for which a physiological function as extracellular messengers has not been identified.

Extracellular nucleoside generation. The actions of ATP and UTP at their respective receptors are terminated by rapid degradation, catalyzed by the ecto-enzyme cascade system, whose last products are Ado and Urd, respectively (Figs. 7 and 8). The time courses of ATP breakdown and ATP catabolites formation, as well as of other NTPs, catalyzed by purified striatal cholinergic synaptosomes [121] and by brain plasma membrane preparation [23, 122] showed that the main regulatory site of extracellular NS generation is the ecto-5'-nucleotidase, the last enzyme of the ectonucleotidase cascade system. This enzyme is highly sensitive to the "feed-forward" competitive inhibition exerted by NTPs, the initial substrates [22, 23, 25]. It might be speculated that at elevated extracellular nucleoside triphosphate concentration, a signal of purine and pyrimidine sufficiency, 
1 extracellular NMPs accumulate, rather than NSs. NSs become available to be transported into

2 astrocytes or neurons by the ENT and CNT systems, and/or delivered into blood stream, when a

3 sufficiently low NTPs concentration is reached, to relieve the inhibition of the ecto-5'-nucleotidase.

4 Intracellular nucleoside metabolic network: adenosine. Brain cytosol almost quantitatively 5 anabolyzes Ado at $1 \mu \mathrm{M}$ initial concentration to AMP, ADP, and ATP, while $100 \mu \mathrm{M}$ Ado is 6 mainly catabolized to Ino and Hyp [23]. Most likely Ado is maintained in the lowest $\mu \mathrm{M}$ level 7 among the other nucleosides [123] by the relative extent of saturation of AdoK (enzyme 3 of Fig.

8 (7)) and AdoD (enzyme 1 of Fig. 7), whose $K_{\mathrm{m}}$ values for Ado are about $0.2 \mu \mathrm{M}$ and $50 \mu \mathrm{M}$, 9 respectively. Thus, the kinase becomes saturated with Ado at low micromolar concentration, and 10 phosphorylates Ado at its $V_{\max }$. Any further increase of uptaken Ado is irreversibly deaminated to 11 Ino [37].

12 Guanosine and inosine. Contrary to Ado, Guo and Ino cannot be phosphorylated at their 5'-position 13 by specific kinases, which are absent in the cytosolic compartment of mammals. They undergo prior 14 phosphorolysis to Hyp and Gua before being converted to their respective NMPs by HPRT (enzyme 1512 of Fig. 7).

Uridine and cytidine. Urd homeostasis is maintained by UrdK (enzyme 1 of Fig. 8), UPase (enzyme 10 of Fig. 8), and by cN-III (enzyme 4 of Fig. 8), which counteracts the activity of UrdK. Cyd is salvaged as such via UrdK, or as Urd, after deamination by Cyd deaminase (9).

\section{CONCLUSIONS}

In most textbooks cytosolic 5'-nucleotidases are considered as pure catabolic enzymes, catalyzing the entry step of purine and pyrimidine nucleotide degradation. New insights into their importance in human metabolism followed the recognition of cN-II hyperactivity in the erythrocytes of LeschNyhan syndrome patients [124]. More recently, it has been shown that activating mutations in cN-II gene NT5C2 are associated with increased nucleoside-analog metabolism and chemotherapy resistance in acute lymphoblastic leukemia [125]. Finally, it should be emphasized that cytosolic 5'nucleotidases may also have a role in the formation of the age-and gender-modulated, regionally different nucleoside level in the brain, with implications for the therapy of many metabolic disorders, in which nucleosides are involved [126]. We hope that the studies described in this review, which is mainly devoted to non experts in the field, will convince the reader that cytosolic 5 '-nucleotidases play a major role in maintaining the qualitative and quantitative balance of 
1 intracellular purine and pyrimidine rings, in nucleotide salvage synthesis, and nucleoside

2 homeostasis and recycling.

3

4

5 ACKNOWLEDGEMENT

6 The authors acknowledge the members of the Unit of Biochemistry of the Department of Biology of

7 the University of Pisa for stimulating discussions. The studies of the authors reported in this review

8 were supported by grants from the Italian "Ministero della Istruzione, Università e Ricerca"

9 (MIUR) and "Regione Sardegna."

\section{ABBREVIATIONS}

12 Ado

$=$ Adenosine

13 AdoD

$=$ Adenosine deaminase

14 AdoK

$=$ Adenosine kinase

15 AMPD

$=$ AMP deaminase

16 AMPK

$=\mathrm{AMP}$ activated protein kinase

$=5$ '-ArabinofuranolylCMP

18 5'-AZTMP

= 5'-AzidoTMP

$19 \quad \mathrm{cN}-\mathrm{IA}$

$=$ AMP preferring 5'-nuclotidase

$20 \quad \mathrm{cN}-\mathrm{II}$

= IMP-GMP preferring 5'-nucleotidse

$21 \quad \mathrm{cN}-\mathrm{III}$

$=$ Uridine-Cytidine preferring 5'-nucleotidase

22 CNT

$=$ Concentrative nucleoside transporters

$=$ Cytidine

24 ENT

$=$ Equilibrative nucleoside transporters

Gua

$=$ Guanine

26 Guo

$=$ Guanosine 


\begin{tabular}{|c|c|}
\hline 1 Нyp & $=$ Hypoxanthine \\
\hline 2 HPRT & $=$ Hypoxanthine-guanine phosphoribosyltransferase \\
\hline Ino & $=$ Inosine \\
\hline $4 \quad \mathrm{~m}(7) \mathrm{GMP}$ & $=7$-Methylguanosine monophosphate \\
\hline NDP & $=$ NucleosideDiPhosphate \\
\hline 6 NMP & $=$ NucleosideMonoPhosphate \\
\hline $7 \quad$ NTP & $=$ NucleosideTriPhosphate \\
\hline $8 \quad \mathrm{NS}$ & $=$ Nucleosides \\
\hline OPC & $=$ OxyPurine Cycle \\
\hline PNC & $=$ Purine Nucleotide Cycle \\
\hline $11 \mathrm{UK}$ & $=$ Uridine-Cytidine kinase \\
\hline 12 UPase & $=$ Uridine phosphorylase \\
\hline 13 Ura & $=$ Uracil \\
\hline $14 \quad$ Urd & $=$ Uridine \\
\hline UrdK & $=$ Uridine kinase \\
\hline
\end{tabular}




\section{REFERENCES}

4 [1] Dobson, J.G. Jr.; Rubio, R.; Berne, R.M. Role of adenine nucleotides, adenosine, and inorganic

5 phosphate in the regulation of skeletal muscle blood flow. Circ. Res., 1971, 29(4), 375-384.

6 [2] Rubio, R.; Berne, R.M; Bockman, E.L.; Curnish, R.R. Relationship between adenosine 7 concentration and oxygen supply in rat brain. Am. J. Physiol., 1975, 228(6), 1896-1902.

8 [3] Latini, C.; Pedata, F. Adenosine in the central nervous system: Release mechanisms and 9 extracellular concentrations. J. Neurochem., 2001, 79(3), 463-484.

10 [4] Cunha, R. A. Adenosine as a neuromodulator and as a homeostatic regulator in the nervous 11 system: different roles, different sources and different receptors. Neurochem. Int., 2001, 38(2),10712125.

13 [5] Burnstock, G.; Fredholm, B.; Verkhratsky, A. Adenosine and ATP receptors in the brain. Curr. 14 Top. Med. Chem., 2011, 11(8), 973-1011.

15 [6] Rathbone, M.; Pilutti, L.; Caciagli, F.; Jiang, S. Neurotrophic effects of extracellular guanosine. 16 Nucleosides Nucleotides Nucleic Acids, 2008, 27(6) 666-672.

17 [7] Lecca, D.; Ceruti, S. Uracil nucleotides: from metabolic intermediates to neuroprotection and neuroinflammation. Biochem. Pharmacol., 2008, 75(10), 1869-1881.

19 [8] Cansev, M.; Marzloff, G.; Sakamoto, T.; Ulus, I.H.; Wurtman, R. J. Giving uridine and/or 20 docosahexaenoic acid orally to rat dams during gestation and nursing increases synaptic elements in 21 brain of weanling pups. Dev. Neurosci., 2009, 31(3), 181-192.

22 [9] Dobolyi, A.; Juhász, G.; Kovács, Z.; Kardos, J. Uridine function in the central nervous system. 23 Curr. Top. Med. Chem., 2011, 11(8), 1058-1067.

24 [10] Cansev, M. Uridine and cytidine in the brain: their transport and utilization. Brain Res. Rev., 25 2006, 52(2), 389-397. 
1 [11] Balestri, F.; Giannecchini, M.; Sgarrella, F.; Carta, M.C.; Tozzi, M.G.; Camici, M. Purine and

2 pyrimidine nucleosides preserve human astrocytoma cell adenylate energy charge under ischemic

3 conditions. Neurochem. Int., 2007, 50(3), 517-523.

4 [12] Giannecchini, M.; Matteucci, M.; Pesi, R.; Sgarrella, F.; Tozzi, M.G.; Camici, M. Uptake and 5 utilization of nucleosides for energy repletion. Int. J. Biochem. Cell Biol., 2005, 37(4), 797-808.

6 [13] Jurkowitz, M.S.; Litsky, M.L.; Browning, M.J.; Hohl, C.M. Adenosine, inosine, and 7 guanosine protect glial cells during glucose deprivation and mitochondrial inhibition: correlation between protection and ATP preservation. J. Neurochem., 1998, 71(2), 535-548.

[14] Tozzi, M.G.; Camici, M.; Mascia, L.; Sgarrella, F.; Ipata, P.L. Pentose phosphates in nucleoside interconversion and catabolism. FEBS J., 2006, 273(6),1089-1101.

11 [15] Reis, M.J. Nucleotidase and its relation to the deamination of nucleotides in the heart and the 12 muscles. Bull. Soc. Chim. Biol., 1934, 16, 385-399.

13 [16] Arch, J.R.; Newsholme, E.A. The control of the metabolism and the hormonal role of 14 adenosine. Essays Biochem, 1978, 14, 82-123.

15 [17] Langer, D.; Hammer, K.; Koszalka, P.; Schrader, J.; Robson, S.; Zimmermann, H. 16 Distribution of ectonucleotidases in the rodent brain revisited. Cell Tissue Res., 2008, 334(2), 19917217. [18] Yegutkin, G. Nucleotide- and nucleoside-converting ectoenzymes: important modulators of purinergic signalling cascade. Biochim. Biophys. Acta, 2008, 1783(5), 673-694.

[19] Truong,V.L.; Collinson, A.R.; Lowenstein, J. M. 5'-Nucleotidases in rat heart. Evidence for occurrence of two soluble enzymes with different substrate specificities. Biochem. J., 1988, 253(1), 117-121.

[20] Skladanowski, A.C.; Newby, A.C. Partial purification and properties of AMP-specific soluble 5'-nucleotidase from pigeon heart. Biochem J., 1990, 268(1), 117-122. pigeon breast muscle cytosolic 5'-nucleotidase-I (cN-I). Acta Biochimica Polonica, 2005, 52(4), 789-796. 
1 [22] Mallol, J.; Bozal, J. 5'-Nucleotidase from bovine brain cortex: effect of solubilization on

2 enzyme kinetics and modulation, Neurochem. Int., 1988, 12(1), 61-67.

3 [23] Barsotti, C.; Ipata, P.L. Metabolic regulation of ATP breakdown and of adenosine production

4 in rat brain extracts., Int. J. Biochem. Cell Biol., 2004, 36(11), 2214-2225.

5 [24] Zimmermann, H. 5'-Nucleotidase: molecular structure and functional aspects. Biochemical J., $6 \quad$ 1992, 285(Pt 2), 345-365.

7 [25] Zimmermann, H. Biochemistry, localization and functional roles of ecto-nucleotidases in the nervous system. Progress in Neurobiology, 1996, 49(6), 589-618.

9 [26] Itoh, R.; Mitsui, A.; Tsushima, K. 5'-nucleotidase of chicken liver. Biochim. Biophys. Acta, $10 \quad \mathbf{1 9 6 7}, 146(1), 151-159$.

11 [27] Pesi, R.; Turriani, M.; Allegrini, S.; Scolozzi, C.; Camici, M.; Ipata, P.; Tozzi, M.G. The 12 bifunctional cytosolic 5'-nucleotidase: regulation of the phosphotransferase and nucleotidase 13 activities. Arch. Biochem. Biophys., 1994, 312(1), 75-80.

14 [28] Pesi, R.; Baiocchi, C.; Allegrini, S.; Moretti, E.; Sgarrella, F.; Camici, M.; Tozzi, M.G.

15 Identification, separation and characterization of two forms of cytosolic 5'-nucleotidase/nucleoside 16 phosphotransferase in calf thymus. Biol. Chem., 1998, 379(6), 699-704.

[29] Itoh, R. IMP-GMP 5'-nucleotidase. Comp. Biochem. Physiol., 1993, 105(1), 13-19.

18 [30] Amici, A.; Magni, G. Human erythrocyte pyrimidine 5'-nucleotidase, PN-I. Arch Biochem 19 Biophys., 2002, 397(2), 184-90.

20 [31] Marinaki, A.M.; Escuredo, E.; Duley, J.A.; Simmonds, H.A.; Amici, A.; Naponelli, V.; 21 Magni, G.; Seip, M.; Ben-Bassat, I.; Harley, E.H.; Thein, S.L.; Rees, D.C. Genetic basis of 22 hemolytic anemia caused by pyrimidine 5'-nucleotidase deficiency. Blood, 2001, 97(11), 3327233332.

24 [32] Bianchi,V.; Spychala, J. Mammalian 5'-nucleotidases. J. Biol. Chem., 2003, 278(47), 461952546198.

26 [33] Nelson, D.L.; Cox, M.M. Principles of Biochemistry, $5^{\text {th }}$ edition, Freiman and Company, 2008 
1 [34] Allsop, J.; Watts, R.W. Purine de novo synthesis in liver and developing rat brain, and the

2 effect of some inhibitors of purine nucleotide interconversion. Enzyme, 1983, 30(3), 172-180.

3 [35] Allsop, J.; Watts, R.W. Purine synthesis and salvage in brain and liver. Advances in

4 Experimental Medicine and Biology, 1984, 165(Pt B), 21-26.

5 [36] Bourget, P.A.; Trembly, G.C. Pyrimidine biosynthesis in rat brain. Journal of Neurochemistry, $6 \quad 1972,19(7), 1617-1624$.

7 [37] Ipata, P.L.; Camici, M.; Micheli, V.; Tozzi, M.G. Metabolic network of nucleosides in the brain. Current Topics in Medicinal Chemistry, 2011, 11(8), 909-922.

9 [38] Sala-Newby, G.B.; Freeman, N.V.E.; Skladanowski, A.C.; Newby, A.C. Distinct roles for 10 recombinant cytosolic 5'-nucleotidase-I and II in AMP and IMP catabolism in COS-7 and H9c2 rat 11 myoblast cell lines. J. Biol. Chem., 2000, 275(16), 11666-11671.

12 [39] Bogan, K.L.; Brenner, C. 5'-Nucleotidases and their new roles in NAD ${ }^{+}$and phosphate 13 metabolism. New J. Chem., 2010, 34, 845-853.

14 [40] Sala-Newby, G.B.; Skladanowski, A.C.; Newby, A.C. The mechanism of adenosine formation 15 in cells. Cloning of cytosolic 5'-nucleotidase-I. J. Biol. Chem. 1999, 274(25), 17789-17793.

16 [41] Chen, W.; Hoerter, J.; Guéron, M. A comparison of AMP degradation in perfused rat heart during 2-deoxy-D-glucose perfusion and anoxia. Part I: the release of adenosine and inosine. J. Mol. Cell Cardiol., 1996, 28(10), 2163-2174.

19 [42] Fredholm, B.B.; Dunwiddie, T.V.; Bergman, B.; Lindstrom, K. Levels of adenosine and 20 adenine nucleotides in slices of rat hippocampus. Brain Research, 1984, 295(1), 127-136.

21 [43] Tomoyuki, K., Takeshi, Y., Yasuhiro, O. The levels of adenosine and its metabolites in the 22 guinea pig and rat brain during complete ischemia-in vivo study. Brain Research, 1998, 787(2), $23 \quad 211-219$. [44] Ljunggren, B.; Ratcheson, R.A.; Siesjo, B.K. Cerebral metabolic state following complete compression ischemia. Brain Research, 1974, 73(2), 291-307. 
1 [45] Phillis J.W.; O'Regan, M.H.; Estevez, A.Y.; Song, D.; VanderHeide, S.J. Cerebral Energy

2 Metabolism During Severe Ischemia of Varying Duration and Following Reperfusion. Journal of

3 Neurochemistry, 1996, 67(4), 1525-1531.

4 [46] Chen.W.; Gueron, M. AMP degradation in the perfused rat heart during 2-deoxy-D-glucose

5 perfusion and anoxia. Part II: the determination of the degradation pathways using an adenosine

6 deaminase inhibitor. J. Mol. Cell Cardiol., 1996, 28(10), 2175-2182.

7 [47] Krebs, H. The Croonian Lecture, 1963: Gluconeogenesis. Proceedings of the Royal Society of 8 London., 1964, 159(977), 545-564.

9 [48] Hardie, D.G.; Ross, F.A.; Hawley, S.A. AMPK: a nutrient and energy sensor that maintains 10 energy homeostasis. Nat. Rev. Mol. Cell Biol., 2012, 13(4), 251-262.

11 [49] Ramaiah, A.; Hathaway, J.A.; Atkinson, D.E. Adenylate as a metabolic regulator effect on 12 yeast phosphofructokinase kinetics. J. Biol. Chem. 1964, 239, 3619-3622.

13 [50] Klinov, S.V.; Kurganov, B.I. Kinetic mechanism of activation of muscle glycogen

14 phosphorylase b by adenosine 5'-monophosphate. Arch. Biochem. Biophys., 1994, 312(1), 14-21.

15 [51] Kurganov, B. I.; Schors, E.I.; Klinov, S.V.; Chebotareva, N.A. Slow step in activation of 16 muscle glycogen phosphorylase b by adenosine 5'-monophosphate. Biochem. Mol. Biol. Int., 1995, 17 36(1), 155-161.

18 [52] Johnson L.N.; Barford, D. Glycogen phosphorylase. The structural basis of the allosteric 19 response and comparison with other allosteric proteins. J. Biol. Chem., 1990, 265(5), 2409-2412.

20 [53] Hofmann, E. The significance of phosphofructokinase to the regulation of carbohydrate 21 metabolism. Rev. Physiol. Biochem. Pharmacol., 1976, 75, 1-68.

22 [54] Hofmann, E.; Kopperschlager, G. Phosphofructokinase from yeast. Methods Enzymol., 1982, $2390(\mathrm{Pt}$ E), 49-60.

24 [55] Uyeda, K. Phosphofructokinase. Adv. Enzymol. Relat. Areas Mol. Biol., 1979, 48, 193-244.

25 [56] Brüser, A.; Kirchberger, J.; Schöneberg, T. Altered allosteric regulation of muscle 626 phosphofructokinase causes Tarui disease. Biochem. Biophys. Res. Commun. 2012, 427(1),133-137. 
1 [57] Hardie, D. AMPK: a key regulator of energy balance in the single cell and the whole

2 organism. Int. J. Obes., 2008, 32(Suppl.4), S7-S12.

3 [58] Winder, W.W. Energy sensing by the AMP-activated protein kinase and its effects on muscle 4 metabolism. J. Appl. Physiol, 2001, 91(2), 1017-1028.

5 [59] Carling, D. The AMP-activated protein kinase cascade: a unifying system for energy control.

6 Trends in Biochem. Sciences, 2004, 29(1), 18-24.

7 [60] Ramamurthy, S.; Ronnett, G. AMP-activated protein kinase (AMPK) and energy-sensing in 8 the brain. Exp. Neurobiol., 2012, 21(2), 52-60.

9 [61] Ahn, Y.J.; Kim, H.; Lim, H.; Lee, M.; Kang, Y.; Moon, S.; Kim, H.S.; Kim, H.H.AMP10 activated protein kinase: implications on ischemic diseases. BMB Rep., 2012, 45(9), 489-495.

11 [62] Bak, M.I.; Ingwall, J.S. Regulation of cardiac AMP-specific 5'-nucleotidase during ischemia mediates ATP resynthesis on reflow. Am. J. Physiol., 1998, 274(Pt 1), C992-C1001.

13 [63] Hancock, C.R.; Brault, J.J.; Terjung, R.L. Protecting the cellular energy state during contractions: role of AMP deaminase. J. Physiol. Pharmacol., 2006, 57(Suppl 10),17-29.

[64] Kulkarni, S.S.; Karlsson, H.K.; Szekeres, F.; Chibalin, A.V.; Krook, A.; Zierath, J.R. Suppression of 5'-nucleotidase enzymes promotes AMP-activated protein kinase (AMPK) phosphorylation and metabolism in human and mouse skeletal muscle. J. Biol. Chem., 2011; $286(40), 34567-34574$.

[65] Plaideau, C.; Liu, J.; Hartleib-Geschwindner, J.; Bastin-Coyette, L.; Bontemps, F.; Oscarsson, J.; Hue, L.; Rider, M.H. Overexpression of AMP-metabolizing enzymes controls adenine nucleotide levels and AMPK activation in HEK293T cells. FASEB J., 2012, 26(6), 2685-2694. [66] Corton, J.M.; Gillespie, J.G.; Hardie, D.G.. Role of the AMP-activated protein kinase in the cellular stress response. Current Biology, 1994, 4(4), 315-324. by low glucose in cell lines derived from pancreatic beta cells, and may regulate insulin release. Biochem. J., 1998, 335(Pt 3), 533-539. catabolism in oxygen-independent muscle contraction. Metabolomics, 2012, 8(1), 1736-1741. 
1 [69] Zhou, G.; Myers, R.; Li, Y.; Chen, Y.; Shen, X.; Fenyk-Melody, J.; Wu, M.; Ventre, J.;

2 Doebber, T.; Fujii, N.; Musi, N.; Hirshman, M.F.; Goodyear, L.J.; Moller, D.E. Role of AMP-

3 activated protein kinase in mechanism of metformin action. J. Clin. Invest., 2001, 108(8), 1167-

41174.

5 [70] Ouyang, J.; Parakhia, R. A.; Ochs, R.S. Metmorfin activates AMP kinase through inhibition of

6 AMP deaminase. J. Biol. Chem., 2011, 286(1), 1-11.

7 [71] Itoh, R.; Yamada, K. Determination of 5'-nucleotidase which preferentially hydrolyses 6-

8 hydroxypurine nucleotides in pig, rat and human tissues by immunotitration. Int. J. Biochem., 1991, 9 23(4), 461-465.

10 [72] Itoh, R.; Echizen, H.; Higuchi, M.; Oka, J.; Yamada, K. A comparative study on tissue 11 distribution and metabolic adaptation of IMP-GMP 5'-nucleotidase. Comparative Biochemistry and 12 Physiology Part B, 1992, 103(1), 153-159.

13 [73] Bretonnet, A.S.; Jordheim, L.P.; Dumontet, C.; Lancelin, J.M. Regulation and activity of 14 cytosolic 5'-nucleotidase II: A bifunctional allosteric enzyme of the Haloacid Dehalogenase superfamily involved in cellular metabolism. FEBS Lett., 2005, 579(16), 3336-3368.

16

[74] Veiga-da-Cunha, M.; Vleugels, W.; Maliekal, P.; Matthijs, G.; Van Schaftingen, E. Mammalian phosphomannomutase PMM1 is the brain IMP-sensitive glucose-1,6-bisphosphatase. J. Biol. Chem., 2008, 283(49), 33988-33993.

[75] Guha, S.K., Rose, Z.B. Brain glucose bisphosphatase requires inosine monophosphate. J. Biol. Chem., 1982, 257(12), 6634-6637.

[76] Guha, S.K.; Rose, Z.B. Role of inosine 5'-phosphate in activating glucose-bisphosphatase. Biochemistry., 1983, 22(6), 1356-1361.

[77] Filoni, D.N.; Pesi, R.; Careddu, M.G.; Camici, M.; Allegrini, S.; Collavoli, A.; Scarfone, I.; Zucchi, F.; Galli, A.; Tozzi, M.G. Initial studies to define the physiologic role of cN-II. Nucleosides, Nucleotides, and Nucleic Acids., 2011, 30(12), 1155-1160.

[78] Wallden, K.; Stenmark, P.; Nyman, T.; Flodin, S.; Graslund, S.; Loppnau, P.; Bianchi, V.; Nordlund, P. Crystal structure of human cytosolic 5'-nucleotidase II: insights into allosteric regulation and substrate recognition. J. Biol. Chem., 2007, 282, 17828-17836. 
2 [79] Wallden, K.; Nordlund, P. Structural basis for the allosteric regulation and substrate recognition of human cytosolic 5'-nucleotidase II. J. Mol. Biol., 2011, 408, 684-696.

[80] Allegrini, S.; Careddu, M.G.; Filoni, D.N.; Camici, M.; Tozzi, M.G. Active and regulatory sites of cytosolic 5'-nucleotidase. FEBS J., 2010, 277, 4863-4872.

[81] Banditelli, S.; Baiocchi, C.; Pesi, R.; Allegrini, S.; Turriani, M.; Ipata, P.L.; Camici, M.; Tozzi, M.G. The phosphotransferase activity of cytosolic 5'-nucleotidase; a purine analog phosphorylating enzyme. Int. J. Biochem. Cell Biol., 1996, 2, 711-720.

[82] Allegrini, S.; Scaloni, A.; Ferrara, L.; Pesi, R.; Pinna, P.; Sgarrella, F.; Camici, M.; Eriksson, S.; Tozzi, M.G. Bovine cytosolic 5'-nucleotidase acts through the formation of an aspartate 52-

[83] Goodman, M.N.; Lowenstein, J.M. The purine nucleotide cycle. Studies of ammonia production by skeletal muscle in situ and in perfused preparations. J. Biol. Chem., 1977, 252(14), 5054-5060.

[84] Van Waarde, A. Operation of the purine nucleotide cycle in animal tissues. Biological Reviews, 1988, 63(2), 259-298.

[85] Ipata P.L. Mechanism of ATP loss in nonoxidative contracting muscle. Adv. Physiol. Educ., 2011, 35, 92-94.

[86] Norman, B.; Glenmark, B.; Jansson, E. Muscle AMP deaminase deficiency in 2\% of a healthy population. Muscle \& Nerve, 1995, 18(2), 239-241.

[87] Fischer, H.; Esbjörnsson, M.; Sabina, R.L.; Strömberg, A.; Norman, B. AMP deaminase deficiency is associated with lower sprint cycling performance in healthy subjects. J. Apll. Physiol., 2007, 103(1), 315-322.

[88] Sahlin, K.; Palmskog, G.; Hultman, E. Adenine nucleotide and IMP contents of the quadriceps

[89] Fukui, H.; Taniguchi, S.I.; Yoshihiko, U.; Yoshida, A.; Ohtahara, A.; Hisatome, I.; muscle in man after exercise. Pflügers Arch., 1978, 374, 193-198. 
1 patients with Hyperthyroidism. The Journal of Clinical Endocrinology \& Metabolism, 2001, 86(5), $2 \quad 2205-2210$.

4 [90] Gaitanos, G.; Williams, C.C.; Boobis, L.H.; Brooks, S. Human muscle metabolism during intermittent maximal exercise. J. Appl. Physiol., 1993, 75, 712-719.

[91] Tullson, P.C.; Teriung, R. Adenine nucleotide degradation in striated muscle. Int. J. Sports Med., 1990, 11, S47-S55.

[92] Dawson, M.J.; Gadian, D.G.; Wilkie, D.R. Muscular fatigue studied by phosphorus nuclear magnetic resonance in the frog. J. Physiol., 1978, 282, 20P-21P.

[93] Stathis, C.G.; Zhao, S.; Carey, M.F; Snow, R.J. Purine loss after repeated sprint bouts in 15

[94] Macedo, D.V.; Lazarim, F.L.; Catanho da Silva, F.O.; Tessuti, L.S.; Hohl, R. Is lactate production related to muscular fatigue? A pedagogical proposition using empirical facts. $A d v$. Physiol. Educ., 2009, 33, 302-307.

[95] Barankiewicz, J.; Gelfand, E. W.; Issekutzg, A.; Cohen, A. Evidence for active purine nucleoside cyclesin human mononuclear cells and cultured fibroblasts. The Journal of Biological Chemistry, 1982, 257(19), 11597-1160.

[96] Berman, P.A.; Human, L. Regulation of 5'-phosphoribosyl-1-pyrophosphate and of hypoxanthine uptake and release in human erythrocytes by oxypurine cycling. J. Biol. Chem., 1990, 265(12), 6562-6568.

[97] Barsotti, C.; Pesi, R.; Felice, F.; Ipata, P.L. The purine nucleoside cycle in cell-free extracts of rat brain: evidence for the occurrence of an inosine and a guanosine cycle with distinct metabolic roles. Cellular and Molecular Life Sciences, 2003, 60(4), 786-793.

[98] Hatanaka, M.; Del Giudice, R.; Long, C. Adenine formation from adenosine by mycoplasmas: adenosine phosphorylase activity. Proc. Natl. Acad. Sci., 1975, 72(4), 1401-1405. 
1 [99] Barsotti, C.; Tozzi, M.G.; Ipata, P.L. Purine and pyrimidine salvage in whole rat brain.

2 Utilization of ATP-derived ribose-1-phosphate and 5-phosphoribosyl-1-pyrophosphate generated in experiments with dialyzed cell-free extracts. Journal of Biol. Chem., 2002, 277(12), 9865-9869.

4 [100] Amici, A.; Emanuelli, M.; Ferretti, E.; Raffaelli, N.; Ruggeri, S.; Magni, G. Homogeneous 5 pyrimidine nucleotidase from human erythrocytes: enzymatic and molecular properties. Biochem. 6 J., 1994, 304(3), 987-992.

8 [101] Grobosky, C.L.; Lopez, J.B.; Rennie, S.B.; Skopelitis, D.J.; Wiest, A.T.; Bingman, C.A.;

9 Bitto, E. Structural Basis of Substrate Specificity and Selectivity of Murine Cytosolic 5'-

10 Nucleotidase III. Journal of Molecular Biology, 2012, 423(4), 540-554.

11 [102] Rees, C.R.; Duley, J.D.; Marinaki, A.M. Pyrimidine 5'-nucleotidase deficiency. British 12 Journal of Haematology, 2003, 120(3), 375-383.

[103] Zanella, A.; Bianchi, P.; Fermo, E. Hereditary pyrimidine 5'-nucleotidase deficiency: from genetics to clinical manifestations. Br. J. Haematol., 2006, 133(2), 113-123.

[104] Rampazzo, C.; Johansson, M.; Gallinaro, L.; Ferraro, P.; Hellman, U.; Karlsson, A.; Reichard, P.; Bianchi, V. Mammalian 5'(3')-deoxyribonucleotidase: cDNA cloning and overexpression of the enzyme in Escherichia coli and mammalian cells. J. Biol. Chem, 2000, 275(8), 5409-5415.

[105] Mazzon, C.; Rampazzo, C.; Scaini, M.; Gallinaro, L.; Karlsson, A.; Meier, C.; Balzarini, J.; Reichard, P.; Bianchi V. Cytosolic and mitochondrial deoxyribonucleotidases: activity with substrate analogs, inhibitors and implications for therapy. Biochem. Pharmacol., 2003, 66(3), 471479.

[106] Beutler, E.; Hartman, G. Age-related red cell enzymes in children with transient erythroblastopenia of childhood and with hemolytic anemia. Pediatr. Res., 1985, 19(1), 44-47.

[107] Hokari, S.; Miyazaki, T.; Hasegawa, M.; Komoda, T. Enhanced activity of pyrimidine 5'nucleotidase in rat red blood cells during erythropoiesis. Biol. Chem., 1998, 379(3), 329-333.

[108] Valentine, W.N.; Anderson, H.M.; Paglia, D.E.; Jaffé, E.R.; Konrad, P.N.; Harris, S.R. Studies on human erythrocyte nucleotide metabolism. II. Nonspherocytic hemolytic anemia, high 
1 red cell ATP, and ribosephosphate pyrophosphokinase (RPK, E.C.2.7.6.1) deficiency. Blood, 1972, $239(5), 674-684$.

4 [109] Valentine, W.N.; Fink, K.; Paglia, D. E.; Harris, S.R.; Adams, W.S. Hereditary hemolytic anemia with human erythrocyte pyrimidine 5'-nucleotidase deficiency. J. Clin. Invest., 1974, 54(4), 866-879.

[110] Paglia, D.E.; Valentine, W.N. Hereditary and acquired defects in the pyrimidine nucleotidase of human erythrocytes. Current topics in hematology, 1980, 3, 75-109. erythrocyte pyrimidine 5'-nucleotidase, $\mathrm{PN}-\mathrm{I}$, is identical to $\mathrm{p} 36$, a protein associated to lupus inclusion formation in response to alpha-interferon. Blood, 2000, 196(4), 1596-1598. immunolocalization of $\mathrm{p} 36$, a new interferon- $\alpha$-induced protein that is associated with human lupus inclusions. J. Biol. Chem., 1996, 271(2), 1118-1126.

[113] Buschmann, J.; Moritz, B.; Jeske, M.; Lilie, H.; Schierhorn, A.;Wahle, E. Identification of Drosophila and Human 7-Methyl GMP-specific Nucleotidases. J. Biol. Chem., 2013, 288(4), 2441-

[114] Parkinson, F.E.; Damaraju, V.L.; Graham, K.; Yao, S.Y.; Baldwin, S.A.; Cass, C.E.; Young, J.D. Molecular biology of nucleoside transporters and their distributions and functions in the brain. Curr. Top. Med. Chem. 2011, 11(8), 948-972.

[115] Balestri, F.; Barsotti, C.; Lutzemberger, L.; Camici, M.; Ipata, P.L. Key role of uridine kinase and uridine phosphorylase in the homeostatic regulation of purine and pyrimidine salvage in brain. Neurochem. Int., 2007, 51(8), 517-523.

[116] Bontemps, F.; Van den Berghe, G.; Hers, H.G. Evidence for a substrate cycle between AMP and adenosine in isolated hepatocytes. Proc. Natl. Acad. Sc., 1983, 80(10), 2829-2833. and drug metabolism. Pharmacology \& Therapeutics, 2005, 107(1), 1-30. 
1 [118] Okuda, H.; Higashi, Y.; Nishida, K.; Fujimoto, S.; Nagasawa, K. Contribution of P2X7

2 receptors to adenosine uptake by cultured mouse astrocytes. Glia, 2010, 58(14), 1757-1765.

3

[120] Ipata, P.L.; Balestri, F.; Camici, M.; Tozzi, M.G. Molecular mechanisms of nucleoside recycling in the brain. Int. J. Biochem. Cell Biol., 2011, 43(1), 140-145.

[121] James, S.; Richardson, P.J. Production of adenosine from extracellular ATP at the striatal cholinergic synapse. J. Neurochem., 1993, 60(1), 219-227.

[122] Ipata, P.L.; Barsotti, C.; Tozzi, M.G.; Camici, M.; Balestri, F. Metabolic interplay between intra- and extra-cellular uridine metabolism via an ATP driven uridine-UTP cycle in brain. Int. J. Biochem. Cell. Biol., 2010, 42(6), 932-937.

[123] Kovács, Z.; Juhász, G.; Palkovits, M.; Dobolyi, A.; Kékesi, K. A. Area, age and gender dependence of the nucleoside system in the brain: a review of current literature Curr. Top. Med. Chem., 2011, 11(8), 1012-1033.

[124] Pesi, R.; Micheli, V.; Jacomelli, G.; Peruzzi L.; Camici, M.; Garcia-Gil, M.; Allegrini, S.; Tozzi, M. G.. Cytosolic 5'-nucleotidase hyperactivity in erythrocytes of Lesch-Nyhan syndrome patients. Neuroreport., 2000, 11(9), 1827-1831.

[125] Tzoneval, G.; Perez-Garcia1, A.; Carpenter, Z.; Khiabanian, H.; Tosello, V.; Allegretta, M.; Paietta, E.; Racevskis, J.; Rowe, J. M.; Tallman, M. S.; Paganin, M.; Basso, G.; Hof, J.; KirschnerSchwabe,R.; Palomero, T.; Rabadan, R.; Adolfo Ferrando, A. Activating mutations in the NT5C2 nucleotidase gene drive chemotherapy resistance in relapsed ALL. Nature Medicine, 2013, 19, 368371.

[126] Kovacs, Z.; Dobolyi, A. Anatomical distribution of nucleoside system in the human brain and implications for therapy. In Adenosine, Susan Masino \& Detlev Boison, Ed.; Springer Science+Business Media New York, 2013, pp.612-656. 
1 Figure 1. Origin, utilization, and recycling of nucleosides. The dephosphorylation by liver cytosolic

25 '-nucleotidases of nucleoside-monophosphates, synthesized de novo in the liver, is the main source

3 of diffusible free nucleosides. Once taken up from the blood into several cell types, including neurons, glial cells, and erythrocytes, that rely on circulating preformed purine and pyrimidine rings rather than de novo synthesis from simple precursors, nucleosides are salvaged to their respective nucleoside-triphosphates by three successive phosphorylation steps, catalyzed by relatively specific kinases. Several allosterically modulated cytosolic 5'-nucleotidases counteract the activity of nucleoside kinases, thus contributing in maintaining AMP, GMP, UMP, and CMP in the proper quantitative and qualitative balance. Finally, nucleosides are generated extracellularly, by the action of an ecto-5'-nucleotidase, the last enzyme of an ecto-enzyme cascade system on exported nucleoside triphosphates. 5'-nulceotidase (1), nucleoside kinase (2), nucleoside monophosphokinase (3), nucleoside diphosphokinase (4), ecto-NTP diphosphohydrolase (5 and 6); ecto-5'-nucleotidase (7).

Figure 2. Pathways of intracellular ATP catabolism and stack plots of the time courses of ATP breakdown and ATP catabolites formation in rat brain post mitochondrial extracts. (A): at normoxic condition, the strong activation exerted by the high ATP level on adenylate deaminase and $\mathrm{cN}-\mathrm{II}$ favours the so called IMP pathway: IMP, rather than AMP accumulates. Moreover, as shown in the inset, any Ado formation is preceded by Ino and Hyp formation, thus excluding a precursor-product relationship between Ado and Ino plus Hyp. (B) At ischemic ATP level, the impaired oxidative phosphorylation favours the activation of $\mathrm{cN}-\mathrm{IA}$ by ADP, and thus the so called adenosine pathway: AMP, rather than IMP accumulates. The enzymes participating in these pathways are: 1, ATPase; 2, adenylate kinase; 3, AMPD; 4, cN-II; 5, PNP; 6, cN-IA; 7 AdoD. Modified from Barsotti and Ipata [23].

Figure 3. Model for the action of $\mathrm{cN}-\mathrm{IA}$ and AMPD in regulating energy metabolism. Normally, energy demand increases ADP concentration (1), and consequently the flow of adenylate kinase towards AMP (2). Binding of AMP activates muscle glycogen phosphorylase (3), muscle and liver 6-phosphofructokinase (4), and AMPK-P (5), the phosphorylated form of AMPK. Phosphorylation and dephosphorylation of AMPK are catalyzed by LKB1 (6) and AMPK-P phosphatase (7), respectively. cN-IA (8), and AMPD (9) modulate the level of intracellular AMP, and thus the Figure 4. The role of PNC and OPC in energy metabolism of the cell. In A, the rate of ADP phosphorylation by glycolysis or oxidative phosphorylation (2) matches the rate of ATP 
1 consumption by ATPase (1) (as in mildly contracting muscle). As a consequence, the intracellular

2 ATP concentration remains constant. In B, an aliquot of the ADP pool is not tightly recycled (as in sustained contraction), and is degraded to IMP by the successive action of adenylate kinase (3) and AMPD (4). The PNC, composed of AMPD, S-AMP synthetase (5), and S-AMP lyase (6) maintains the purine ring in phosphorylated non diffusible forms, thus favouring a rapid ATP replenishment at rest, during recovery. In C, an IMP aliquot, which is not recycled by the PNC (as in strenuous contraction), enters the OPC, composed of cN-II (7), PNP (8) and HPRT (9), and is broken down to non phosphorylated purines. An aliquot of the two diffusible non phosphorylated purines, Hyp and Ino, enters the blood stream and is excreted by urine.

Figure 5. The OPC in action. The initial reaction mixture contained $100 \mu \mathrm{M}$ Ino, $5 \mathrm{mM}$ Pi, $2 \mathrm{mM}$ PRPP, $8.3 \mathrm{mM} \mathrm{Mg}^{2+}$, and $1.15 \mathrm{mg} / \mathrm{ml}$ proteins of cytosolic brain extract, at $\mathrm{pH}$ 7.4. During PRPP consumption (dotted line), the three components of the cycle, Ino, Hyp, and IMP, attain a steadystate level, suggesting that they are continuously recycled. However, after PRPP is massively consumed, the cycle collapses, IMP is broken down, and Ino and Hyp accumulate.

Modified from Ref. 97

Figure 6. The role of the UPase-UK-cN-III system on the reciprocal regulation of purine and pyrimidine salvage synthesis in brain. The rationale stands i) on the widely accepted idea that pyrimidine salvage occurs at the nucleoside level (mostly Urd), while purine salvage is a PRPPmediated process, occurring at the nucleobase level, and ii) on the modulation exerted by UTP and CTP, the final products of the pyrimidine salvage synthesis, on UK. Relatively high cytosolic UTP and CTP levels, a signal of pyrimidine sufficiency, inhibit UK, shifting the equilibrium of UPase towards Urd phosphorolysis. The substrate cycle UMP-Urd-UMP is no longer operative, and any UMP is catabolized to uracil, rather than being recycled. Rib-1-P is then transformed into PRPP, which is used for purine salvage synthesis. On the contrary, at relatively low UTP and CTP levels, uptaken Urd is mainly anabolized to uracil- and cytosine-nucleotides. cN-III counteracts the activity of UK, thus contributing to the homeostatic regulation of Urd. The enzymes participating in the pathway are: UK (1); UPase (2); NS monophosphokinase (3); NS diphosphokinase (4); CTP synthetase (5); cN-III (6); phosphoribomutase (7); PRPP synthetase (8); HPRT and APRT (9 and 10), adenylate kinase (11).

Figure 7. Cross talk between extra- and intracellular milieu for purine nucleoside recycling in brain. ATP and GTP are released from cytosolic vesicles into the extracellular space and broken down to Ado and Guo, respectively, by ectonucleotidase. Ado, once taken up, is phosphorylated at its 5' 
1 position via AdoK. The AMP product is phosphorylated by adenylate kinase. Any excess Ado is

2 deaminated by AdoD. Guo is salvaged as Gn via PRPP-mediated HPRT. Two relatively specific

3 kinases, NS monophosphokinase and NS diphosphokinase, catalyze the successive phosphorylation

4 of GMP to GTP. The enzymes participating in these pathways are: AdoD (1); PNP (2); AdoK (3);

5 adenylate kinase (4); AMP preferring 5'-nucleotidase $\mathrm{cN}$-IA (5); ecto-NTP diphosphohydrolase (6

6 and 8); ecto- NS pyrophosphatase diphosphohydrolase, (7); ecto-5'-nucleotidase (9);

7 phosphoribomutase (10); PRPP synthetase (11); HPRT (12); NS monophosphokinase (13); NS

8 diphosphokinase (14); IMP-GMP preferring 5'-nucleotidase $\mathrm{cN}-\mathrm{II}$ (15). Cylinders represent the NS

9 transporters CNT or ENT. $\mathrm{P}_{2} \mathrm{Y}_{2} \mathrm{P}_{2} \mathrm{Y}_{4}, \mathrm{P}_{2} \mathrm{X}_{7}$ and $\mathrm{P} 2 \mathrm{Y}_{11}$ represent subtypes of the $\mathrm{P} 2 \mathrm{Y}$ and $\mathrm{P} 2 \mathrm{X}$

10 family receptors.

11 Figure 8. Cross talk between extra- and intracellular milieu for pyrimidine nucleoside recycling in

12 brain. UTP and CTP are released from cytosolic vesicles into the extracellular space and broken

13 down to Urd and Cyd, respectively, by ecto-nucleotidase. Once taken up, Urd and Cyd are

14 phosphorylated at their 5' position via Urd-Cyt kinase. UMP and CMP are either converted back to

15 Urd and Cyd, or phosphorylated by NS monophosphokinase and NS diphosphokinase, respectively.

16 Cyd, which is transported less efficiently than Urd, may be salvaged as Urd after deamination by

17 Cyd deaminase. Any excess Urd undergoes phosphorolysis by Urd phosphorylase. The enzymes

18 participating in these pathways are : Urd-Cyt kinase (1); NS monophosphokinase (2); NS

19 diphosphokinase (3), UMP-CMP preferring 5'-nucleotidase (cN-III) (4); ecto-NTP

20 diphosphohydrolase (5 and 7), ecto-NS pyrophosphatase diphosphohydrolase (6); ecto-5'-

21 nucleotidase (8); Cyd deaminase (9); Urd phosphorylase (10); UDPG pyrophosphorylase (11).

22 Cylinders represent the NS transporters CNT or ENT. UDPG, Urd diphosphoglucose; G 1-P,

23 glucose-1-P. $\mathrm{P} 2 \mathrm{Y}_{2} \mathrm{P}_{2} \mathrm{Y}_{4}, \mathrm{P}_{2} \mathrm{Y}_{6}$ represent subtypes of the $\mathrm{P} 2 \mathrm{Y}$ family receptors. 


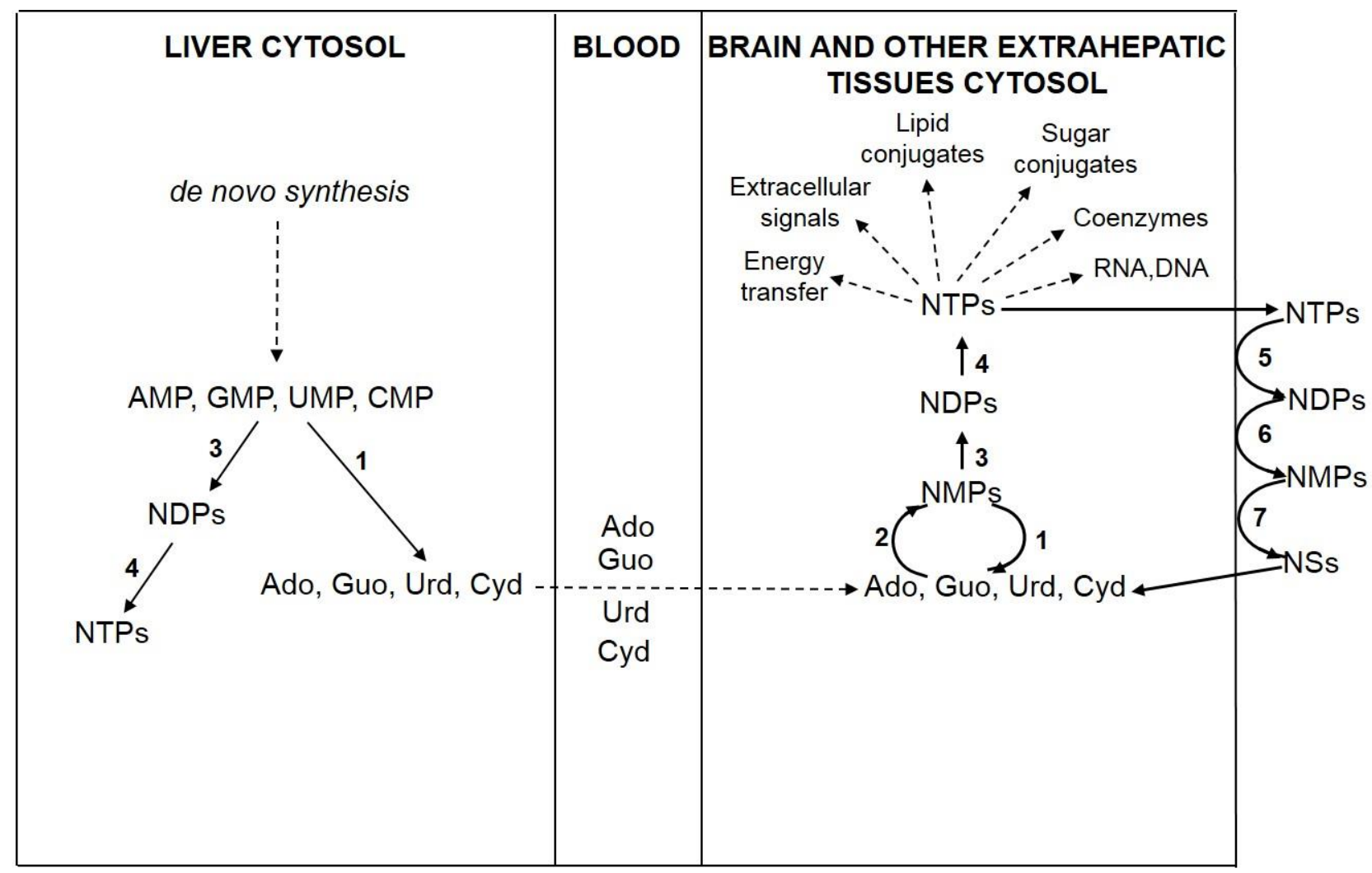

$3 \quad$ Figure 1

4

5

6

7

8

9 
A

NORMOXIC ATP LEVEL ( $5 \mathrm{mM})$

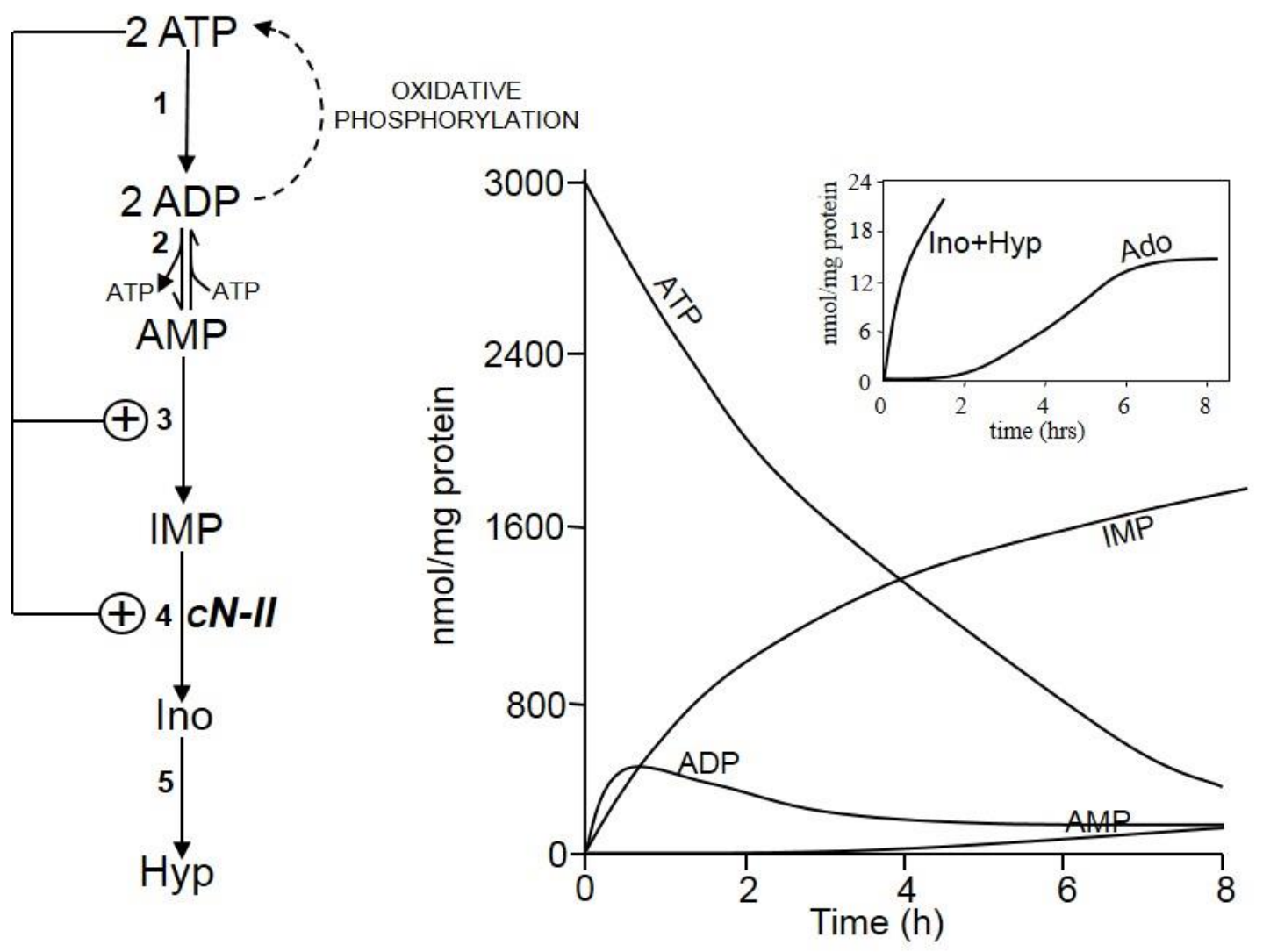

B ISCHEMIC ATP LEVEL (2-0.5 mM)

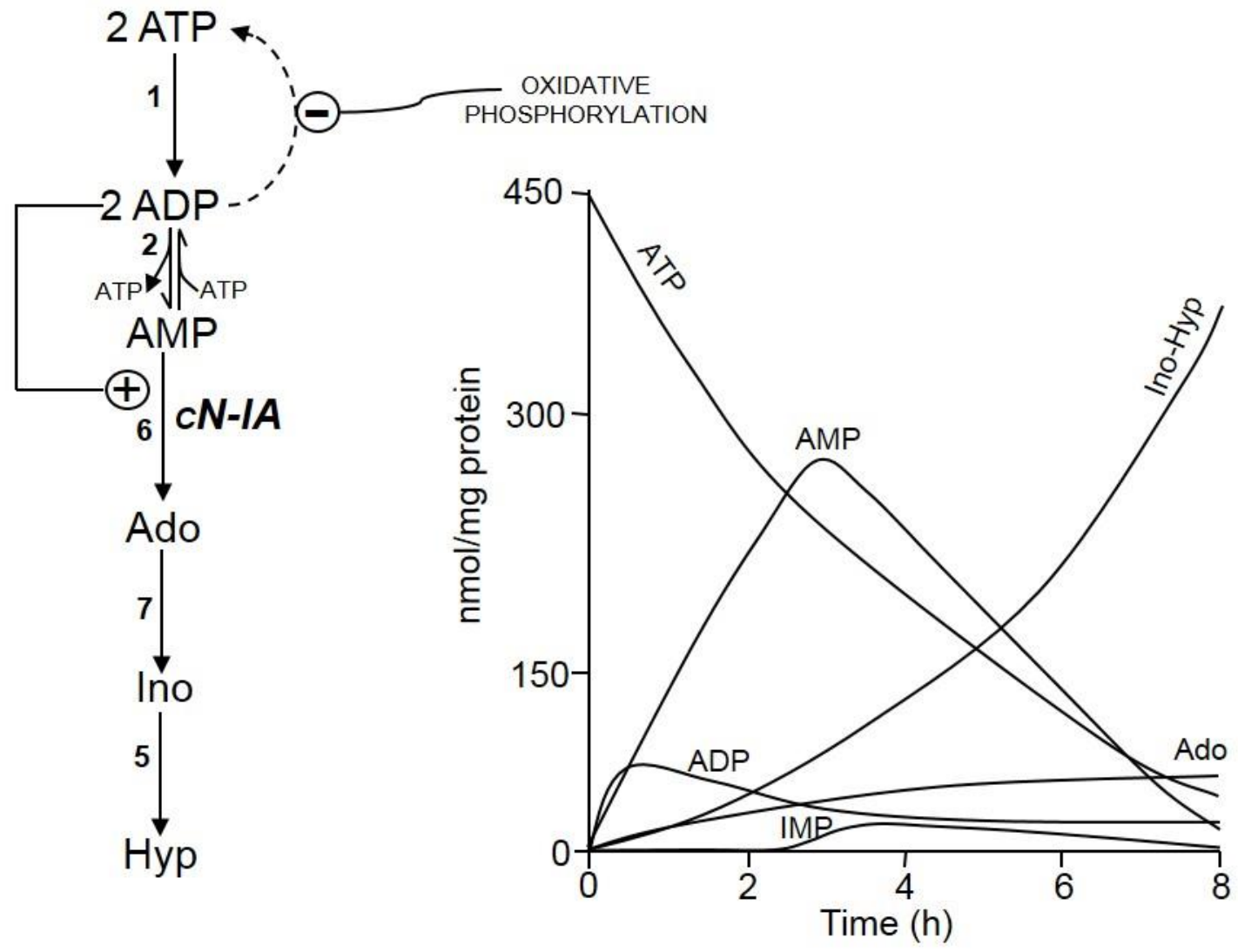




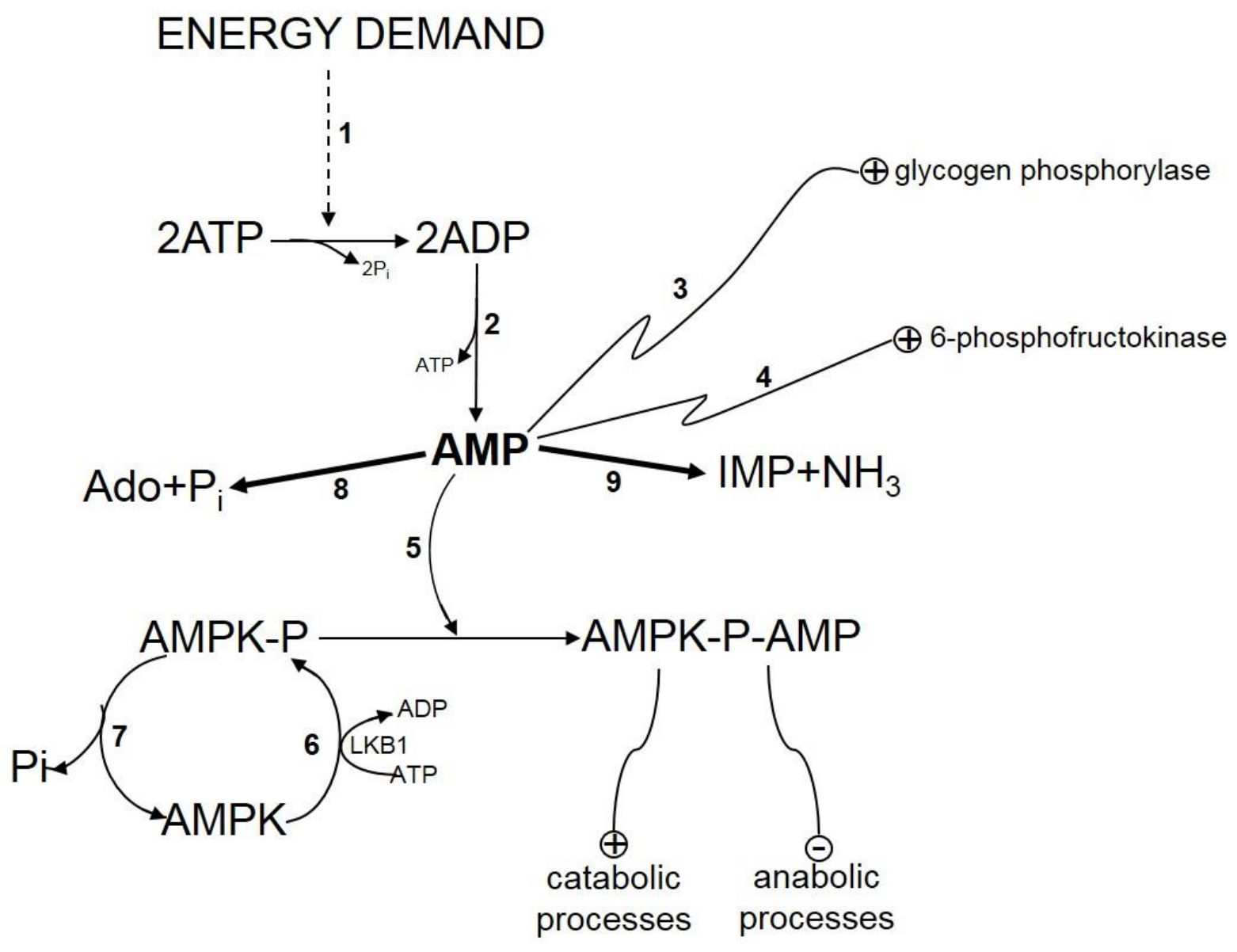

Figure 3

3

4

5

6

7

8

9 
1

2

3


$4 \quad$ Figure 4

5

6

7

8

9

10 


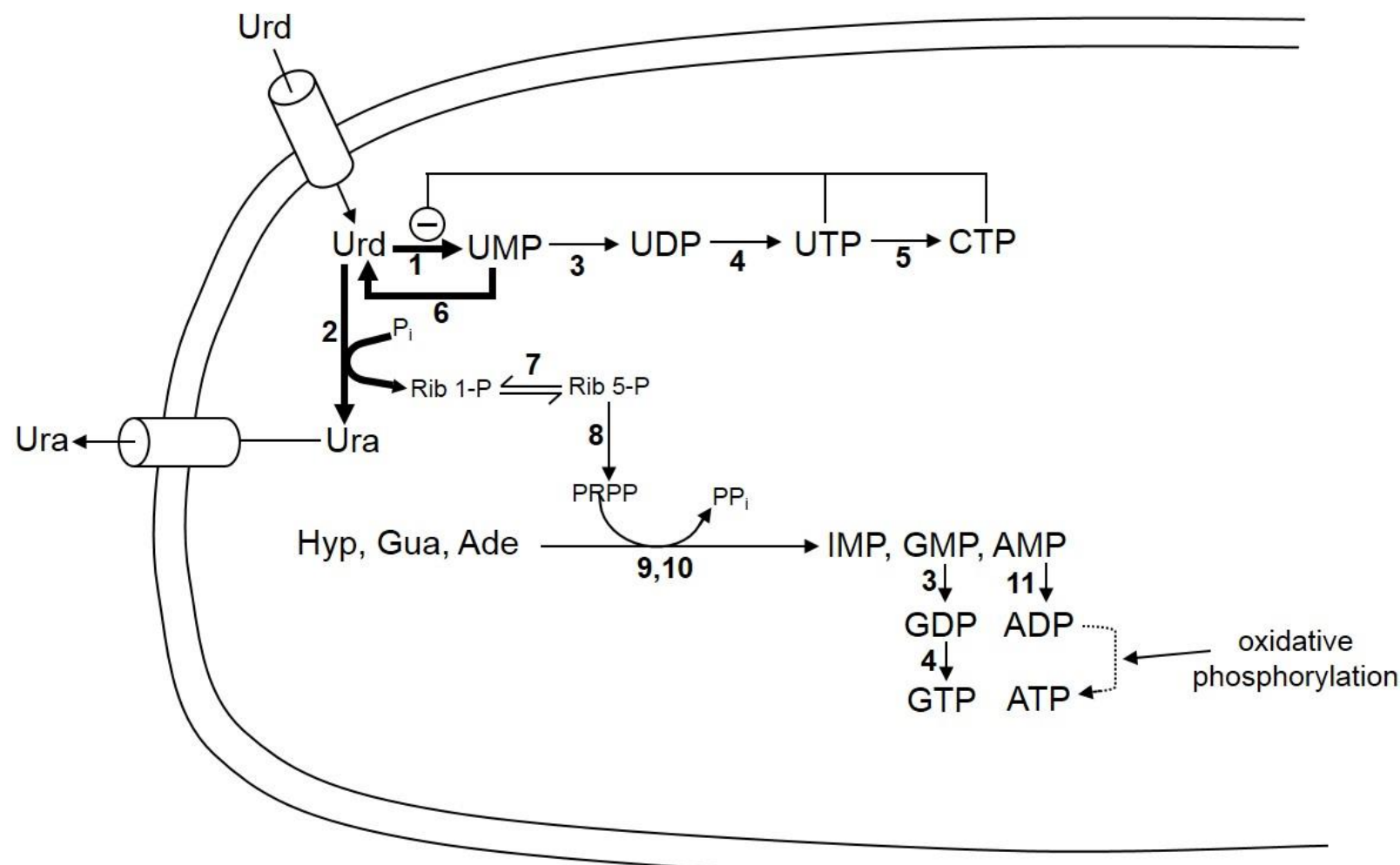

Figure 5

4

5

6

7

8

9

10

11 
$1 \quad$ Figure 6

2

3

4

5

6

7

8

9

10

11 
Figure 7

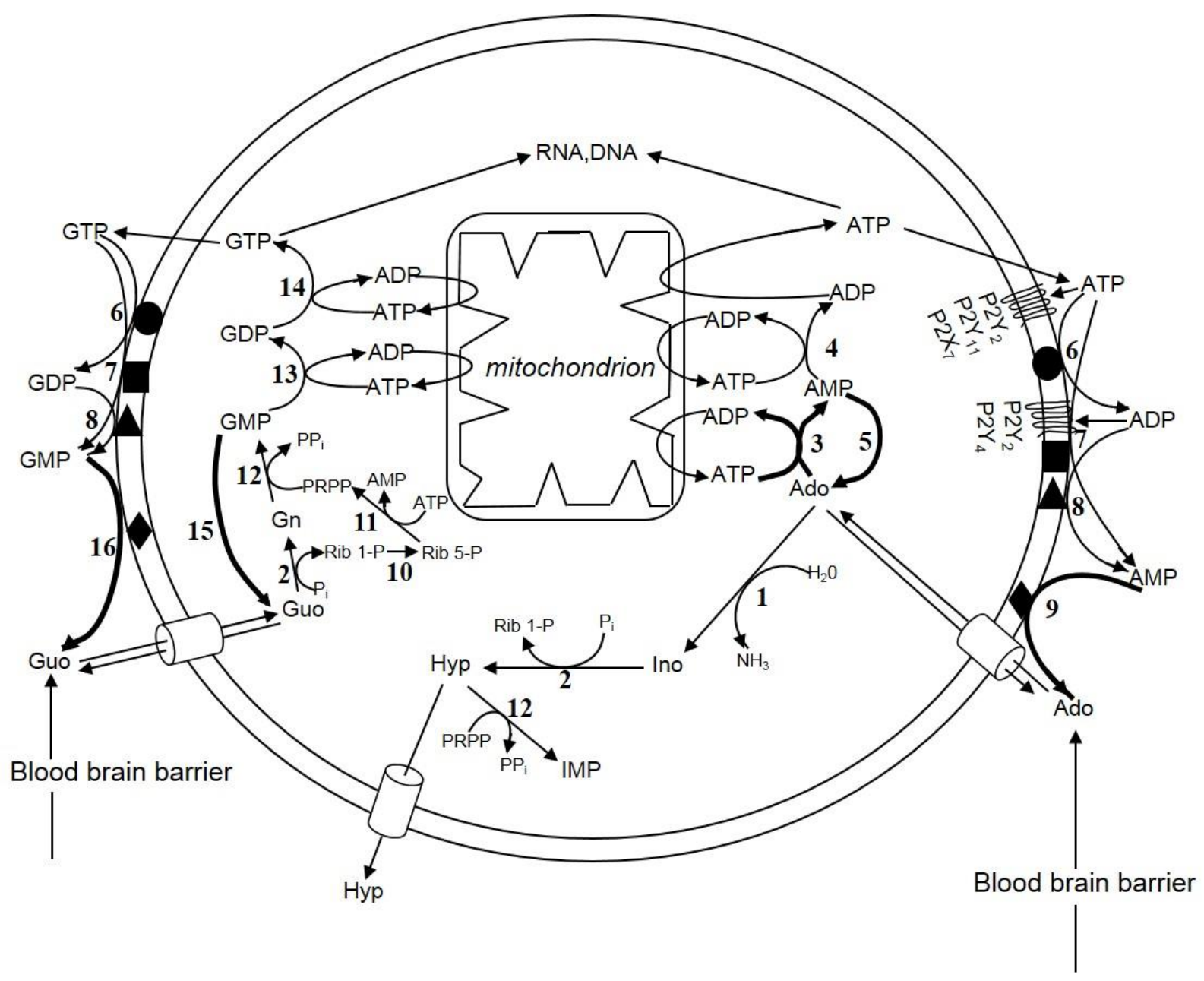




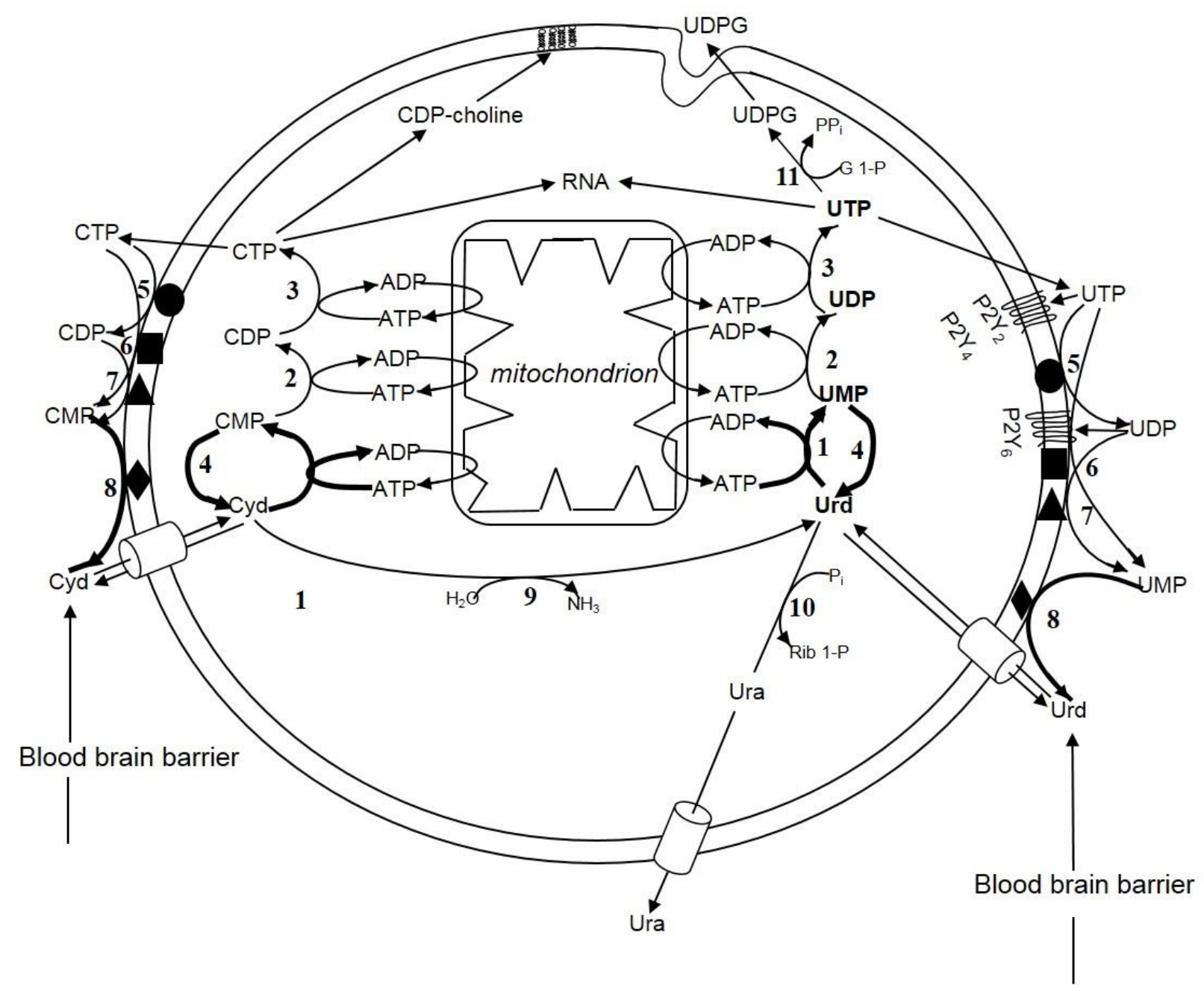

$3 \quad$ Figure 8 